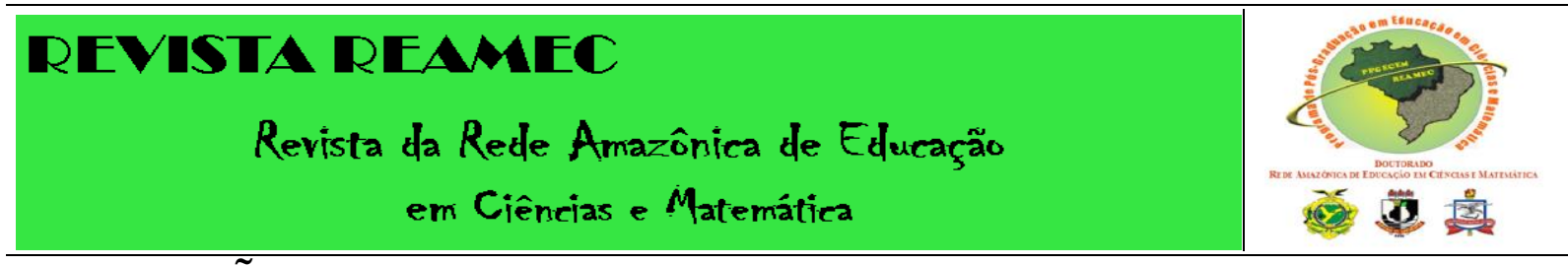

\title{
FORMAÇÃO CONTINUADA (LATO SENSU) DE PROFESSORES- GESTORES ESCOLARES: RELATO DE UMA EXPERIÊNCIA VIVENCIAL
}

\section{CONTINUED EDUCATION (LATO SENSU) OF TEACHERS-SCHOOL MANAGERS: REPORT OF A LIVING EXPERIENCE}

\author{
Silas Borges Monteiro ${ }^{28}$ \\ Polyana Olini ${ }^{29}$
}

\begin{abstract}
RESUMO
Este artigo se mostra como um relato de experiência construído sobre a realização do Curso de Especialização em Gestão Escolar, vinculado ao Programa Nacional Escola de Gestores da Educação Básica Pública, na Universidade Federal de Mato Grosso na modalidade de Educação a Distância. Com foco na experiência do projeto vivencial, relata-se a proposição e o desenvolvimento de múltiplos e simultâneos processos de interação desta formação continuada, nos quais procurou-se aprofundar temáticas relevantes para a compreensão dos fundamentos da gestão democrática, bem como para problematização dos fatores e condicionantes que interferem na prática da gestão escolar.
\end{abstract}

Palavras-Chave: Formação Continuada. Gestão Escolar. Educação a Distância. Projeto Vivencial.

\section{ABSTRACT}

This paper presents a case studies built on the realization of the course Specialization in School Management, linked to the National School Program of Managers of Basic Public Education, at the Federal University of Mato Grosso in distance education mode. With the focus on living project experience, the proposition and development of multiple and simultaneous processes of interaction of this formation, in which we tried to deepen the understanding of relevant thematic foundations of democratic management, as well as to questioning of the factors and conditions that interfere with the practice of school management.

Keywords: Continuing Education. School Management. Distance Education. Living Project

\section{INTRODUÇÃO}

\footnotetext{
${ }^{28}$ Doutor em Educação pela Universidade de São Paulo. Professor Associado da Universidade Federal de Mato Grosso. Coordenador do Curso de Especialização em Gestão Escolar - Programa Escola de Gestores.

${ }^{29}$ Mestre em Educação pela Universidade Federal de Mato Grosso. Doutoranda em Educação pela Universidade Federal do Rio Grande do Sul, na área de Currículo.

Revista REAMEC, Cuiabá - MT, n.05, Volume 1, dezembro 2016, ISSN: 2318 - 6674

Revista do Programa de Doutorado da Rede Amazônica de Educação em Ciências e Matemática

http://revistareamec.wix.com/revistareamec
} 


\section{REVISTA REAMEC}

\section{Revista da Rede Amazônica de Educação \\ em Ciências e Matemática}

Os debates dos anos 1990 foram cruciais para mostrar a importância da formação contínua dos professores (HUBERMAN, 1995; ESTEPA et. all., 2005; PIMENTA, 1999). Para além de culpabilizar o professor (NÓVOA, 1999), as pesquisas mostravam a importância da formação de excelência na qualidade destinada aos docentes, como um elemento constituinte da sua profissão. Esse debate levou à proposição de projetos de formação em nível lato sensu de professores do ensino fundamental como sendo considerada, no Brasil, necessária, inclusive expressa na Lei de Diretrizes e Bases da Educação de 1996. Vinculada a isso, existe a ideia de que um processo mais intenso nessa direção poderá trazer benefícios substanciais à melhoria da qualidade de ensino, portanto, à melhoria da produtividade da educação pública, ao menos no nível de ensino aqui colocado.

A proposição de projetos de formação continuada para docentes não teria, inicialmente, grandes impactos no ensino fundamental, caso não viesse acompanhada de outras iniciativas no sentido de promover modificações substanciais nos processos de Gestão Escolar e, sobretudo, nas condições em que são produzidos os saberes pedagógicos.

Nesse contexto, a realização de cursos de formação continuada, para os profissionais que atuam na área da educação, indica elementos ou fatores que podem interferir construtivamente nas práticas pedagógicas, consequentemente, na constituição de determinada identidade profissional dos professores.

E quando falamos de professores, no caso do Mato Grosso, falamos de profissionais que, democraticamente, podem assumir a gestão de suas escolas. Assim, ao lado da formação contínua para a docência deve ter em vista que se faz necessária a formação para a gestão de escolas públicas, uma dimensão que, geralmente, fica ao largo dos cursos de formação inicial para o magistério, seja no Curso Normal, seja na educação superior.

Temos consciência da limitação dos denominados "projetos de formação" quando propõem ações circunscritas a uma ou outra faceta do que significa "ser professor" ou "ser gestor", promovendo, quando muito, formações restritas a determinados aspectos da docência ou da administração escolar como os de caráter mais instrumentalizadores do ensino ou de pouca - ou nenhuma - ligação com os cotidianos escolares. 


\section{REVISTA REAMEC}

\section{Revista da Rede Amazônica de Educação \\ em Ciências e Matemática}

Atualmente, ao analisar a universidade, nota-se a fraca relação entre a educação superior e os problemas sociais, fato que tem sido explicado pelo modelo de universidade europeu - referenciado no ideal de "produção do conhecimento desinteressado", conforme apregoavam os filósofos da Grécia antiga. Esse modelo, entrou em conflito com o modelo americano de universidade que defendia o conhecimento aplicável, "prático" (CHAUI, 2001). Tal polarização expressa, por um lado, a formação que valoriza o ideal de cultura e saber e, por outro, a ênfase na profissionalização para responder às demandas de ordem prática da sociedade.

Tendo em vista que as demandas de responsabilidade do diretor e do vice-diretor de uma escola não tem origem somente no cotidiano escolar, mas na realidade educacional como um todo, na atividades que compreendem desde o atendimento de famílias, os casos de indisciplina e violência até ao trabalho de articulação e integração dos processos educativos escolares, concebemos, na realização do Curso de Especialização em Gestão Escolar, a importância do fortalecimento do trabalho coletivo e reflexivo e das relações democráticas como partes de um processo de formação continuada preocupado com a consolidação e a mobilização de saberes para atender a sociedade e contribuir com o desenvolvimento profissional.

Para além dos projetos de formação seus princípios, proposições e o significado das ações formativas, vemos surgir experiências que se utilizam, crescentemente, da modalidade de Educação a Distância (EAD) como suporte para seu desenvolvimento. Esse tipo de ação favoreceu e favorece um debate bastante promissor sobre a formação de professores, mas cria, ao mesmo tempo, posicionamentos "apaixonados" ou indiferença sobre os rumos e encaminhamentos que se possam dar sobre o assunto.

Com esta reflexão, também um relato de experiência, sobre a realização deste Curso de Especialização em Gestão Escolar, bem como sobre o uso da EAD, aspiramos, em um primeiro momento, contribuir com a base de dados sobre as experiências nacionais nesse campo e, posteriormente, indicar possibilidades e limites afim de contribuir com propostas que definem bases comuns de formação, entendendo que a apropriação de determinados princípios formativos por parte das universidades, poderá assim continuar assegurando e fomentando políticas e programas consistentes como este. Para tanto, nos focaremos no espaço que a disciplina/sala ambienteprojeto vivencial proporcionou; integrando os conteúdos 


\section{REVISTA REAMEC}

Revista da Rede Amazônica de Educação

em Ciências e Matemática

teórico-práticos, estudados no decorrer do curso, bem como os elementos do cotidiano escolar dos professores-gestores.

\section{A ESPECIALIZAÇÃO EM GESTÃO ESCOLAR NA UNIVERSIDADE FEDERAL DE MATO GROSSO}

No meio acadêmico, vemos surgir experiências que se utilizam, crescentemente, da modalidade de Educação a Distância como suporte para seu desenvolvimento. A aposta nessa modalidade favorece um debate bastante promissor sobre a formação de professores e os demais campos de estudos da educação. O Curso de Especialização em Gestão Escolar, que faz parte das ações do Programa Nacional Escola de Gestores da Educação Básica Pública, é uma dessas experiências. Inserido nas ações do Plano de Desenvolvimento da Educação (PDE). O Programa teve início, em 2005, com o Curso piloto de Extensão em Gestão Escolar de 100h, ofertado pelo Instituto Nacional de Estudos e Pesquisa Anísio Teixeira (INEP).

A proposição de projetos de formação, em nível lato sensu, de professores do ensino fundamental é considerada hoje no Brasil, como necessária, à medida que a Lei de Diretrizes e Bases da Educação aponta para tal assertiva (BRASIL, 1996).

A legislação brasileira preconiza que a gestão do espaço escolar deve ser democrática e participativa. O Plano Nacional de Educação (PNE) vai além ao postular como uma de suas metas para a gestão; estabelecer a colaboração dos municípios e das universidades para "formar cinquenta por cento dos professores da educação básica em nível de Pós-Graduação lato e stricto sensu e garantir a todos formação continuada em sua área de atuação" (BRASIL, 2011, p. 45). Vinculada a isso, acredita-se que um processo mais intenso nessa direção poderá trazer benefícios razoáveis à melhoria da qualidade de ensino, portanto, na melhoria da produtividade da educação pública.

Neste sentido, a realização da Especialização em Gestão Escolar mostrou-se baseada no ordenamento jurídico do país, pois a Universidade Federal de Mato Grosso (UFMT) junto a seu Instituto de Educação, desenvolveu o curso no Estado de Mato Grosso em parceria com o Ministério da Educação (MEC). As vagas foram distribuídas em regime de colaboração com a Secretaria de Estado de Educação, Esporte e Lazer (SEDUC) e a União dos Dirigentes Municipais de Educação (UNDIME) de Mato Grosso. Totalizando 20\% dos cursistas selecionados pela primeira e $80 \%$ pela segunda, com até dois participantes por escola, 


\section{REVISTA REAMEC}

Revista da Rede Amazônica de Educação

em Ciências e Matemática

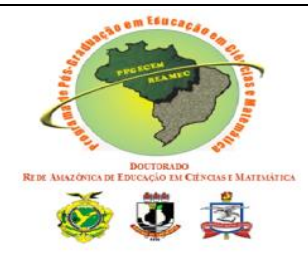

perfazendo um total de 400 vagas. Dessa forma, o Trabalho foi realizado em arranjo interinstitucional entre SEDUC, UNDIME e UFMT, em âmbito regional.

Essa especialização lato sensu destinou-se aos profissionais graduados, portadores de Licenciatura Plena - em qualquer área do conhecimento - que integram a equipe gestora, em exercício, de escolas das redes estaduais e municipais de ensino de Mato Grosso. Por se tratar 111 de um Estado de território extenso, as vagas se concentram em 10 turmas-polos de EAD. Esses polos foram delineados por critério de proximidade dos municípios, de acordo com as regiões do Estado. São eles: 1. Alta Floresta; 2. Barra do Garças; 3. Cáceres; 4. Confersa; 5. Cuiabá; 6. Várzea Grande; 7. Juína; 8. Tangará da Serra; 9. Rondonópolis e 10. Sinop.

Estamos em tempo de novas tecnologias que apontam para a necessidade de romper com os sistemas que se caracterizam por compreensões redutoras como a de Moore (1977), que entende a EAD como uma metodologia que promoveria o surgimento de alunos mais independentes e autônomos em seu cotidiano de estudos, ou como a de Peters (1989), que propõe que o ensino a distância deveria se caracterizar como um sistema industrial na produção de ofertas formativas.

Para melhor compreensão do entendimento de EAD que conduziu o curso, no que diz respeito à organização das atividades de formação, é imprescindível que se recorra às literaturas que tratam do desenvolvimento dessa modalidade a partir dos elementos que a fundam. Primeiramente, o estabelecimento de processos de comunicação e interlocução, que suportam a não presencialidade de alunos e professores, possibilitando que a proposta promova e assegure a interação e a interatividade entre seus atores de modo que a aprendizagem seja efetiva. E depois as tecnologias que sustentam esse mesmo processo de comunicação.

Enquanto para Moore (1977) os sistemas de EAD devessem desenvolver e apoiar a busca da autonomia antes da aprendizagem, Peters (1989) afirma ser necessária a aprendizagem, desde que, provida por um "ensino industrializado" fundado em formas técnicas e pré-fabricadas de comunicação. Essa forma industrializada de compreender e gerir a EAD traria também uma serie de problemas em aspectos que implicam ou tem consequência sobre alunos e professores, como proletarização, desqualificação e divisão do trabalho. 


\section{REVISTA REAMEC}
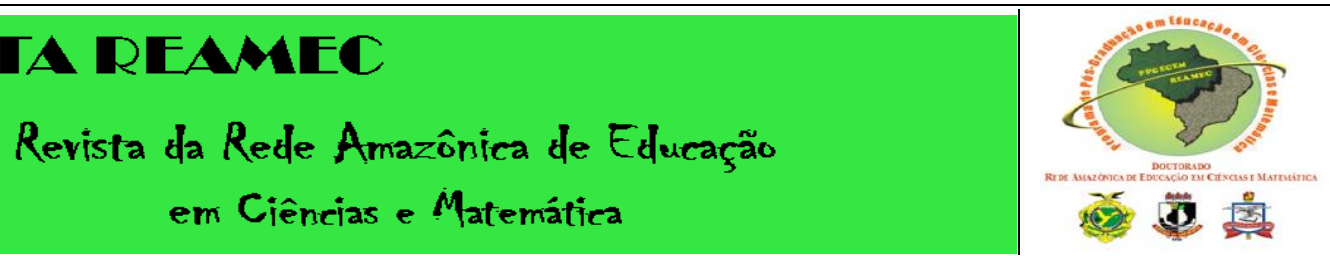

Conforme Garrison (1993), o industrialismo didático que marcou a EAD, acabou também por excluir um processo transformador quanto aos impactos da modalidade nos sistemas presenciais. $\mathrm{O}$ fato é que a crise por que passam as universidades convencionais e, mais particularmente, as dedicadas exclusivamente a EAD faz com que novas alternativas sejam pensadas. Dentre essas novas alternativas o provimento de cursos na modalidade a distância pelas universidades convencionais determinaria outra, forma de pensar a organização desses sistemas formativos.

Nessa perspectiva, a ideia de trabalhar em sistemas integrados - entre presencial e não presencial - prepara os recursos materiais e humanos já disponíveis e permitir um diálogo mais próximo e complementar entre essas duas modalidades de ensino, passa a ganhar força. Martin Rodriguez (1999) afirma que a integração desses sistemas propicia avanços significativos, tanto no uso das tecnologias da informação e comunicação, como na busca de alternativas para o atendimento de um contingente maior de pessoas no nível superior de ensino.

Dessa forma, a oferta do curso, na modalidade EAD, pela UFMT, contou com o planejamento e a realização de momentos presenciais, como desdobramento da estratégia de democratização do acesso e descentralização de recursos financeiros, efetivada pelo MEC/FNDE. No geral os encontros presenciais ocorreram de acordo com a necessidade de cada turma-polo, sendo obrigatória a realização de no mínimo dois; respectivamente, de avaliação e de orientação de Trabalho de Conclusão de Curso (TCC). Além do encontro destinado as sessões públicas de defesa TCC.

Ao longo do desenvolvimento da formação continuada, ofereceu-se uma proposta de trabalho oriunda de múltiplos e simultâneos processos de interação, em que procuramos aprofundar temáticas relevantes para a compreensão dos fundamentos da Gestão Democrática, dos fatores e condicionantes que interferem na prática da gestão escolar no Estado, bem como oportunizar conhecimento e domínio de processos, procedimentos e ferramentas tecnológicas que podem ampliar e tornar mais efetiva a sua gestão no cotidiano escolar.

Como orienta o Projeto Pedagógico da Especialização em Gestão Escolar (BRASIL, 2009), sua organização curricular foi trabalhada por temáticas relacionadas em três eixos vinculados entre si, quais sejam: 1. o direito à educação e a função social da escola básica; 2 . 


\section{REVISTA REAMEC}

\section{Revista da Rede Amazônica de Educação \\ em Ciências e Matemática}

políticas de educação e a gestão democrática da escola; 3. Projeto Político Pedagógico e práticas democráticas na gestão escolar. Ademais, sete componentes curriculares, desenvolvidos em salas ambiente, integraram esses eixos, os quais foram organizados de maneira que possibilitassem a reflexão e apropriação dos conteúdos curriculares por parte dos cursistas, bem como, o acompanhamento e a avaliação das atividades didático-pedagógicas por parte dos professores, supervisores e tutores. São eles: 1. Introdução ao ambiente virtual e ao curso; 2. Fundamentos do direito à educação; 3. Políticas e gestão na educação; 4. Planejamento e prática da gestão escolar; 5. Tópicos especiais de políticas e programas de educação: PNE, PDE e PAR; 6.Oficinas tecnológicas; 7. Projeto vivencial.

O curso foi organizado e realizado na plataforma moodle, onde cada uma das turmaspolo foi composta com uma média de quarenta cursistas, contando com uma equipe pedagógica formada por dois professores pesquisadores, dois supervisores e um tutor presencial. Visando a qualidade do ensino-aprendizagem, a sistematização do trabalho da equipe pedagógica de cada turma-polo deu-se de maneira que um dos professores pesquisadores era o responsável pelos componentes curriculares, enquanto o outro pelo componente curricular integrador, isto é, pelo projeto vivencial. Os dois supervisores também representaram o arranjo institucional regional do curso, sendo um da SEDUC e outro da UNDIME de Mato Grosso. O acompanhamento dos cursistas foi feito pela equipe gestora, equipe pedagógica, as supervisoras, os tutores presencias e a secretaria de curso. Contudo, diante da proximidade local com os cursistas, o trabalho dos tutores presenciais foi imprescindível para o funcionamento desse acompanhamento.

Com dois professores pesquisadores, em cada uma das dez turmas-polo, foi possível atender aos componentes curriculares em blocos temáticos, permitindo o desenvolvimento do curso no contexto da prática profissional do cursista. O acompanhamento constante do conteúdo integrador nas etapas de projeto vivencial, também foi possível, diante dessa disposição da equipe, que, durante todo o curso, fez de tudo para que fosse promovido o diálogo entre as temáticas e conteúdos das salas ambientes com o Projeto Político Pedagógico das escolas nas quais os cursistas atuavam.

As temáticas e atividades que integram os três eixos foram introduzidas pelos professores coordenadores das salas ambiente por meio da elaboração de um Guia Didático, que visava orientar os professores pesquisadores e os cursistasa explorar as diferentes 


\section{REVISTA REAMEC}

\section{Revista da Rede Amazônica de Educação \\ em Ciências e Matemática}

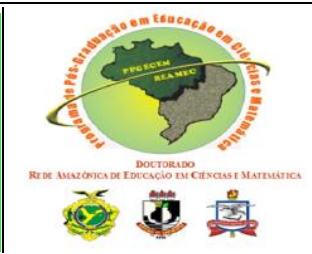

possibilidades de interação, conforme o tipo de atividade solicitada. Os Guias foram construídos sob a orientação dos coordenadores do curso, a partir do conteúdo disponibilizado pelo MEC e das especificidades de cada uma das turmas-polo. Para além das formalidades acadêmicas, a escritura desse material sempre primou pelo estilo dos coordenadores adjuntos, de modo que os professores pesquisadores, tutores e cursistas pudessem "sentir sua presença" no Ambiente Virtual de Aprendizagem. Provocando o desejo de conhecer e instigando a curiosidade pelo componente curricular.

Cada um dos Guias Didáticos foi elaborado com os seguintes itens: a) um breve texto, em formato de carta de boas-vindas, com pertinente apresentação do trabalho a ser desenvolvido durante o período da sala ambiente; b) enunciação e descrição das atividades, bem como orientações para realizá-las; c) descrição dos critérios de avaliação das atividades e leituras. d) apresentação de material bibliográfico a ser estudado na sala ambiente; e) indicações de textos e vídeos complementar.

Antes do início de cada sala ambiente, na plataforma online do curso, foram realizados encontros presenciais de formação dos professores pesquisadores. Planejados e ministrados pelos professores coordenadores adjuntos, esses encontros promoviam apresentação e discussão acerca dos conteúdos e temas das salas ambiente e dos seus respectivos Guias Didáticos. Foram importantes para a efetivação do ensino-aprendizagem, pois garantiram o estudo do conteúdo de integração da sala ambiente e dos textos complementares selecionados previamente pelo coordenador. Além do que, também permitiam a troca de experiências entre os professores pesquisadores de todas as turmas-polo. Esses movimentos não cessavam ao término de cada encontro presencial, pois se estendiam na plataforma moodle em uma sala denominada espaço pedagógico, na qual dava-se continuidade ao discutido presencialmente, bem como esclarecimento de eventuais dúvidas sobre a realização das atividades propostas e seus critérios de avaliação.

Tanto nos encontros presenciais de formação dos professores pesquisadores, quanto no espaço pedagógico, buscou-se dar atenção às ferramentas de fórum na qualidade de espaços de trocas de conhecimento, ideias, discussão, debates e dúvidas. Enquanto um espaço de aprendizagem, os fóruns propostos nas salas ambiente somente cumprem seu papel quando há interações, por isso o acompanhamento das postagens e o envio de respostas foram priorizados, visando incentivar a participação dos cursistas. 


\section{REVISTA REAMEC}

\section{Revista da Rede Amazônica de Educação \\ em Ciências e Matemática}

No intuito de formar, em nível de pós-graduação lato sensu, diretores e vice-diretores educacionais, em efetivo exercício nas escolas públicas da Educação Básica o curso se apoiou no trabalho desenvolvido na sala ambiente projeto vivencial para articular e fortalecer o diálogo entre teoria e prática na práxis do cursista. O trabalho do cursista nessa sala ambiente se desenvolveu desde o início do curso, em seis etapas que se integraram com as demais salas ambientes e culminando no TCC.

O TCC foi uma atividade obrigatória aos cursistas do Curso de Pós-Graduação em Gestão Escolar da UFMT, portanto faz parte de sua estrutura curricular. Tratou-se da redação e defesa de um artigo acadêmico-científico, baseado em trabalho de pesquisa individual sob orientação do professor pesquisador responsável pelo eixo de trabalho do projeto vivencial. Tal artigo teve como exigência de seu desenvolvimento um apoio dos aportes teóricos e metodológicos estudados durante o curso, num movimento de intervenção na realidade da escola onde o professor-gestor e pós-graduando atuam. As defesas dos TCCs, foram públicas e realizada por meio da apresentação de pôsteres, perante banca examinadora, composta por dois membros, do corpo docente do curso.

Diante dos aspectos apresentados aqui, é possível dizer que o Curso de Especialização em Gestão Escolar, não trabalhou de maneira dissociada seu currículo de pósgraduação lato sensu e sua modalidade de ensino a distância. Dessa forma, ambas as dimensões estão integradas, o que criou uma realidade peculiar no que se refere a formação continuada e a

organização das atividades mobilizadas para esse fim, como pressupostos para criação de novas possibilidades de formação. Possibilidades que ultrapassem o caráter meramente instrumentalizador da gestão escolar, ao considerar fundamental o dialogo com a dinâmica presente no fenômeno educativo e nos diversos cotidianos escolares.

\section{INTERVENÇÃO E PESQUISA POR MEIO DA FORMAÇÃO VIVENCIAL}

Na proposta nacional do Programa Escola de Gestores a sala ambiente projeto vivencial tem o objetivo de proporcionar apoio para que os cursistas organizem uma intervenção, vinculada a elaboração do Projeto Político-Pedagógico da Escola (PPP) das escolas, sob a orientação do professor responsável, tal produção fomenta a elaboração e o 


\section{REVISTA REAMEC}

\section{Revista da Rede Amazônica de Educação \\ em Ciências e Matemática}

desenvolvimento o TCC. Na UFMT esse componente curricular foi desenvolvido como eixo articulador da formação dos professores-gestores escolares, a partir do entendimento de que "da universidade à escola, o processo de construção da identidade profissional exige o aprofundamento da gestão democrática, o respeito à pluralidade conceitual, a ampliação dos espaços de reflexão coletiva e de inserção política e social” (DUTRA, 2008, pp. 21-22).

Utilizando-se dessa perspectiva, as $120 \mathrm{~h}$ previstas pelo MEC foram desenvolvidas em seis etapas de trabalho, cada uma delas aconteceu concomitantemente e articuladamente com as outras salas ambientes do curso. Tendo em vista que as escolas abrangidas pelo curso, através da participação de seus gestores estudantes de especialização, já possuíam o PPP, o propósito do projeto vivencial na UFMT foi realizar pesquisas com vistas à reelaboração do planejamento escolar, avaliação do impacto da realização da gestão democrática no cotidiano escolar. Cada uma das etapas do projeto vivencial construiu uma vivência ativa e crítica da fundamentação teórica, do debate e da troca de experiência presentes no curso no âmbito das outras disciplinas, contribuindo para intervenções na escola e delimitação do TCC. Tal vivência dependeu da sensibilização e mobilização da comunidade, diagnóstico da escola, planejamento, implementação e avaliação do projeto de pesquisa que os cursistas desenvolveram em seus TCCs.

A reorganização da proposta do MEC consistiu em meio de múltiplos e simultâneos processos de interação, nos quais procurou-se aprofundar temáticas relevantes para a compreensão dos fundamentos da gestão democrática, bem como para problematização dos fatores e condicionantes que interferem na prática da gestão escolar. Além disso, oportunizou aos cursistas conhecimento e domínio de processos, procedimentos e ferramentas tecnológicas que podem ampliar e tornar mais efetiva a gestão da escola em que o cursista exerce sua atividade profissional como dirigente, por meio, da aplicação integradora do apreendido na sala ambiente Oficina Tecnológica.

Destaca-se também o funcionamento da sala Ambiente Tópicos Especiais Políticas e Programas de Educação: PNE, PDE e PAR, em parceria com o projeto vivencial, por oferecer aos professores-gestores elementos teóricos e metodológicos que visavam aprofundar os conhecimentos sobre políticas públicas estabelecidas em programas e projetos nacionais, que influenciam diretamente o PPP das escolas em que atuam. Neste sentido, as atividades buscaram estimular esse cursista a analisar; o PNE, identificando o contexto político da época 


\section{REVISTA REAMEC}

\section{Revista da Rede Amazônica de Educação \\ em Ciências e Matemática}

em que foi elaborado, sua tramitação no Congresso Nacional, suas propostas e os vetos presidenciais feitos a ele; o PDE, por meio da identificação de seus pressupostos teóricos e metodológicos, assim como o alcance de suas ações e o possível impacto sobre a realidade educacional; o Plano de Metas Compromisso Todos pela Educação; o Índice de Desenvolvimento da Educação Básica (IDEB) e o Plano de Ações Articuladas (PAR) buscando por suas articulações e sua concretização na realidade. Para além das leituras individuais e dos debates coletivos, esse trabalho vivencial oportunizou aprendizados sobre o caráter determinante do planejamento na educação, nos diversos níveis da administração pública, bem como a reflexão sobre a importância do PPP, como forma de planejamento na construção de uma gestão democrática e na melhoria da qualidade da educação.

Assim, como nos outros componentes curriculares, as leituras, fóruns e produções dessa sala ambiente priorizaram a qualificação do cursista na perspectiva da gestão democrática e da efetivação do direito à educação escolar básica com qualidade social. As etapas do projeto vivencial problematizaram a elaboração ou a reformulação do PPP, abordando as situações conflitivas e a prática pedagógica, vivenciadas no cotidiano da escola, em suas relações com as políticas públicas educacionais e o planejamento. Daí entende-se que essa sala ambiente concretizou a criação de espaço de vivência e de ação que possibilitou aos cursistas aexperimentação de práticas de gestão e de pesquisa e intervenção.

A experiência comprova que muito do desejo e da decisão em dar continuidade à formação no campo da gestão escolar pode ser explorado nas etapas de projeto vivencial. Esses movimentos caracterizaram um processo de transformação que, a partir do proposto por um programa nacional, esteve aberto à necessidade de transformação que cada gestor escolar diagnosticou na escola em que atuava. Assim, esse trabalho vivencial de pesquisa, de formação e de intervenção, no planejamento e no cotidiano escolar, se assume crítico ao lançar mão da pesquisa-ação, uma vez que percebe a transformação, nas escolas participantes,

como necessária a partir dos trabalhos iniciais do pesquisador com o grupo, decorrente de um processo que valoriza a construção cognitiva da experiência, sustentada por reflexão crítica coletiva, com vistas à emancipação dos sujeitos e das condições que o coletivo considera opressivas (FRANCO, 2005, p. 485).

O estudo e a vivência do trabalho de gestão e, consequentemente, do trabalho de pesquisa-ação dos professores-gestores escolares foi vivenciado como um exercício profissional, coletivo e reflexivo, uma vez que a gestão educacional é um exercício, que exige 


\section{REVISTA REAMEC}

\section{Revista da Rede Amazônica de Educação \\ em Ciências e Matemática}

profissionalização e formação continuada. Assim como é comum encontrarmos pessoas que assumem a docência convencidos de que podem ensinar pelo simples fato de que dominam o conteúdo que lhes é designado, encontramos profissionais que acreditam bastar assumir o cargo de diretor ou vice-diretor educacional para desenvolverem trabalho eficaz de gestão e de reflexão sobre o direito à educação. Relata-se, por meio da experiência do projeto vivencial, que o fazer do gestor na escola, bem como o fazer pedagógico e a docência, possui saberes próprios e identidade própria.

O fazer do professor-gestor escolar é uma ação social, portanto sua avaliação não deve se restringir ao exame individual. Nos espaços virtuais de debate, destinados a troca de experiências entre os professores coordenadores das salas ambiente, os professores pesquisadores e os cursistas alcançou-se o interesse dos cursistas por aperfeiçoamento e teorização do processo de organização do trabalho educativo, e suas interfaces com a qualidade da educação e a autonomia da escola.

\section{REFERÊNCIAS}

BRASIL. Lei de Diretrizes e Bases da Educação Nacional, Lei no 9.394, de 20 dez 1996.

BRASIL. Projeto de Lei do Plano Nacional de Educação (PNE 2011/2020): projeto em tramitação no Congresso Nacional/PL no 8.035/2010/organização: Márcia Abreu e Marcos Cordiolli. - Brasília: Câmara dos Deputados, Edições Câmara, 2011.

Brasil. MEC/SEB/Diretoria de fortalecimento Institucional de Gestão Educacional. Programa Nacional Escola de Gestores da Educação Básica Pública. Projeto de Especialização em Gestão Escolar (Lato Sensu). Projeto de Curso. Brasília: Revisado em maio de 2009.

CHAUI, Marilena. Escritos sobre universidade. São Paulo: Editora UNESP, 2002.

DUTRA, Juçara Vieira. Verbos intransitivos para uma política pública: Formar, valorizar, profissionalizar. Entrevista. In: Revista Retratos da Escola. v. 2, n. 2-3. Jan/dez 2008.

FRANCO, Maria Amélia Santoro. Pedagogia da pesquisa-ação. In: Educação e Pesquisa. São Paulo, v.31, n. 3, p. 483-502, set./dez. 2005.

GARRISSON, D. R. Quality and access in distance education: theorical considerations". In: KEEGAN, D. (ed). Theorical principles of distance education. Londres, Routledge, 1993.

HUBERMAN, Michäel. O ciclo de vida profissional dos professores. In: NÓVOA, A. (Org.). Vidas de professores. 2. ed. Porto, Portugal: Porto Ed., 1995. 


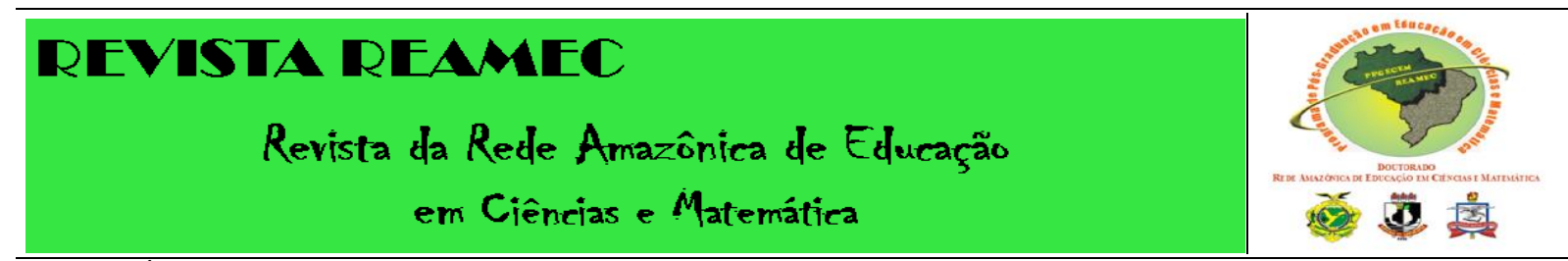

MARTÍN-RODRIGUEZ, E. Dilemas y supuestos teóricos-prácticos del desarrollo institucional de la educación a distancia. In: MARTIN-RODRIGUEZ et QUINTALLÀN, Manuel (Coord.) La educación a distancia en tiempos de cambios: nuevas generaciones, viejos conflictos. Proyecto Didáctico Quirón. Ediciones de la Torre, Madrid, 1999.

MOORE, M. On a Theory of independent study. Hagen, EIFF, 1977.

NÓVOA, António. Os Professores na Virada do Milênio: do excesso dos discursos à pobreza das práticas. Educação e Pesquisa, São Paulo, v. 25, n. 1, 1999.

PETERS, O. The Iceberg Has Not Melted: Further Reflections on the Concept of Industrialization and Distance Teaching. In: Open Learning, vol 4, n. 3, 1989.

PIMENTA, Selma Garrido. Saberes Pedagógicos e atividade docente. São Paulo: Cortez, 1999. 